\title{
COLEG: Collaborative Learning Environment within Grid
}

\author{
Yacine Lafifi ${ }^{1}$, Khaled Halimi ${ }^{1}$ and Mourad Hadjeris ${ }^{2}$ \\ ${ }^{1}$ LAIG Laboratory, Department of Computer Science, University of Guelma, Algeria \\ ${ }^{2}$ Department of Computer Science, University of Guelma, Algeria
}

\begin{abstract}
The principal function of the CSCL environments is to provide to the various users (students, teachers, tutors, etc.) the best activities with the best tools at the best time according to their needs. If a CSCL system is a collection of activities or learning process, we can cut out its functionalities in a certain number of autonomous functions which can then be carried out separately in the form of autonomous applications by using the technology of the Web/Grid services. The emerging technologies based on the Grid are increasingly being adopted to improve education and provide better services for learning. These services are offered to students who, regardless of their computer systems, can collaborate to improve their cognitive and social skills. This article presents COLEG (COllaborative Learning Environment within Grid), which aims to employ the capacities offered by the Grid to give the various actors all the power of learning, collaboration and communication in an adaptable, heterogeneous and dynamic sight.
\end{abstract}

Keywords: Grid, CSCL, collaborative learning, Grid service, Grid portal

\section{Introduction}

Collaborative learning [21] is a process in which participants acquire new skills and build new knowledge by means of the interactions that take place within the members of a group. This pedagogical approach can be considered to be more effective than individual and competitive learning under many circumstances [45].

Computer Supported Collaborative Learning (CSCL) [48] is a discipline devoted to research in educational technology that focuses on the use of Information and Communication Technologies within the context of collaborative learning. As a result of the efforts made in this research domain, many systems have been proposed in order to support the realization of different collaborative learning situations. These systems, called Collaborative Learning Systems, typically offer an environment with several tools that users may employ to accomplish some learning activities of a given situation [11]. But in most cases, these collaborative learning systems have lots of drawbacks and limitations, such as: the non consideration of adaptability, reusability, integration of tools and learning resources available in different places, use of hardware resources, group awareness and so on.

The most desirable features of a collaborative learning system are: adaptability, flexibility and ubiquity. A computer application is said to be adaptable or flexible if it provides end-users with some means to modify its functionalities, in order to better fit their needs [56]. In this sense, tailorable collaborative learning systems enable teachers and/or students to easily integrate external tools in order to support the realization of new situations [69].

These features can be supported by the Grids. Several researchers promote the use of their concepts in the field of collaborative learning $[3,4$, $6,14,47,51,52,62,63,67,68]$. In fact, Grid has many interesting aspects for the development of collaborative learning. In addition to the capabilities available to support collaboration and communication among participants, the Grid technology facilitates the sharing, the deposit and the retrieval of learning objects as well as files transfer with a high speed and for big distances. 
The use of Grid services in learning environments helps to tackle the three important problems of CSCL systems mentioned above (i.e. adaptability, flexibility and ubiquity). Grid technology is required in many collaborative learning situations. For instance, consider a medical school where students learn collaboratively to operate. In such a scenario, supercomputing capabilities are required in order to compute high-quality visualizations of a complex human body model, which is collaboratively manipulated by students in real time, and to display the computation result on remote screens [12].

Through the adoption of the Grid technologies it is possible to achieve a wide-scale learning resource sharing in heterogeneous and geographically distributed environments, the implementation of learning organizations in which different actors (universities, teachers, learners), share a common target, and are able to cooperate to obtain a result [15].

It is in these two contexts (i.e. CSCL and Grid) that our work steps inside. It aims at developing a collaborative learning environment under the Grid infrastructure that can easily be adapted by teachers, tutors and learners to support their own situations of collaboration. Several limitations of the current collaborative learning systems previously mentioned can be eliminated or at least their negative effects can be reduced.

The tools integrated in our environment called COLEG (for COllaborative Learning Environment within Grid) are not restricted in terms of possibilities of supercomputing or with the specific needs for material. This is done to enable the tools integration offered as services by providers in the context of a grid computing [7] and facilitating the collaboration, learning and monitoring processes. Significantly, the use of a grid infrastructure allows tools to access large amounts of computing power or specific material resources all the time [11]. Moreover, COLEG provides more adaptability and flexibility, a good control of the learning process with a set of services (collaboration, tools integration, etc.) and the dynamic services creation provided by the Factory Service.

This work is a part of a global project which consists of proposing a collaborative learning environment based on Grid technology and IMS-LD
(Instructional Management Systems-Learning Design) specifications that can be used by all Algerian universities. The task dedicated to our team is to propose a CSCL system, which enjoys the benefits of Grid technology (reducing computing time and increasing storage capacity). The whole idea is to implement a collaborative teaching system that will be used by the universities in Algeria. By using our environment, these universities can facilitate courses management and encourage the collaboration between students, teachers and tutors. To achieve our objectives, we opted for using open source products (Grid portal, middleware, Learning Management System, etc.).

The goal of this paper is to present the architecture of COLEG as well as its functioning through the presentation of a set of scenarios of use. The rest of this paper is organized as follows. In Section 2, we analyze the needs of the CSCL platforms as well as the study of using Grid services in the CSCL research field. Then, we describe in Section 3 the architecture of COLEG as well as its components. We point some works using the Grid in the field of CSCL in Section 4 and we present a comparative study between existing systems and COLEG. Finally, we conclude in Section 5.

\section{CSCL and Grid}

\subsection{Needs of CSCL Platforms}

The principal objective of a collaborative learning platform is to improve the quality of learning and not to replace the traditional modes. The means to achieve this goal are multiple, complementary and independent. They preserve their autonomy: access to various resources, offer the tutoring services remotely, communication tools, resolution of exercises, remotely exchanges and collaboration.

A platform is an information system, which must satisfy needs and answer criteria [60] such as: to be based on the Internet technologies, to satisfy the standards (LOM, IMS, SCORM, etc.), to allow the management of several types of learning activities (courses, exercises, communication), not to require a very high flow of 
communication and not to require the installation of a particular software on the client station. This type of systems gathers tools necessary to the principal users, namely the teacher, the student and the administrator. These devices ultimately ensure the remote consultation of learning contents, the individualization and the follow-up of the learning, and the interactions between the three types of users.

Several systems supporting such or such strategy were developed. These Computer Supported Collaborative Learning systems present several disadvantages. Their principal problem relates to the tools and the manners to support the various actors of such systems in the extensible, open, dynamic, adaptable and heterogeneous environments. Hence, for a collaborative learning environment to be able to satisfy the real needs of its actors, it must fulfill the following requirements: flexibility, reusability, modification of a learning scenario during the execution time, adaptability, the tools integration, decreasing of technical problems, the materials integration, the group awareness and the communication one-to-one and one-to-many.

\subsection{Basics of Grid Computing and Grid Services}

Grid computing focuses on resource sharing and social policies. Resource sharing in Grid computing primarily focuses on direct access to computers, software, data, and other resources, as required by various collaborative problem-solving and resource-brokering strategies emerging in industry, science, and engineering [30]. Social policies of Grid computing mean that each Grid node can have its own hardware and software specifications, storage devices, network topologies, and so on [25]. Also, the word "Grid" often means "computational grid". A computational grid is a hardware and software infrastructure that provides dependable, consistent, pervasive, and inexpensive access to high-end computational capabilities [28].

Providing an alternative perspective, Ian Foster [26] considers that Grid computing involves "coordinated resource sharing and problem solving in dynamic, multi-institutional virtual organizations". These shared resources can include computing resources, data, network bandwidth, and so on [53].

Significantly, a new technology appeared recently: Grid Services (GS). This technology belongs to the oriented-services paradigm and allows the deployment of the Grid infrastructures [7] in which the multiple organizations can share the heterogeneous resources. In other words, resources of infrastructures extending from the data and the files to the scientific instruments, the display devices, the computers, and the giant computers are offered by providers in the form of Grid Services.

The technology of Grid services which combines the Grid computing and the web services presents a new trend for the development of the CSCL applications. The Grid Service gathers the heterogeneous, dynamic, and distributed resources from various places and completes the significant division of the resources of the Grid. In addition, because the Grid service has some advantages which web service misses, it provides a better solution to the problems of the resource sharing of learning and collaboration in the CSCL applications.

\subsection{Inputs of the Grid Technology in the CSCL}

The Grid provides a new paradigm of access to resources that overcomes the limitations of distribution web-based client/server model. Indeed, unlike the current web, in a Grid environment it is possible for each participating entity to be both client and server, which is a major asset in a learning environment where participants should strongly collaborate and share or exchange the learning resources. The distribution approaches based web services are limited in availability, scalability and distribution of resources [55, 61].

The ultimate goal of a grid is to transform the world network of computers in immense resources and unified processing capacity [6]. According to Rob Bjornson and Andrew Sherman [8], a grid allows users to collect and organize the disparate resources into a visual entity more consistent and more manageable, and to make these virtual resources available simultaneously to multiple users. This definition of the grid is entirely consistent with the requirements of 
a CSCL system, which are collaboration and communication among all participants. In other words, during an online learning, there must be ways that enable interaction between the entities involved in the learning.

Education is considered to be a "very natural and important application of grid technologies" [31], and CSCL is one of the major research fields in technology-enabled education. The analysis of main grid characteristics [10] also supports the idea that the use of a grid infrastructure can provide major benefits for CSCL applications: large scale of grid infrastructures, wide distribution of resources, inter-organization relationship support and heterogeneous nature of shared resources are some of the most relevant characteristics of grid computing for the CSCL domain.

Several works have examined how to apply grid service technologies to e-learning. For example, Reklaitis developed a framework based on Globus and used it to develop a grid environment for e-learning [62]. Gaeta and his colleagues also developed some concepts for employing grid technologies to integrate learning resources [33]. Furthermore, Pankratius and Vossen [61] proposed an architecture for an elearning grid environment and they introduced the notion of grid learning object.

Considering the benefits provided by Grid, it is possible for educational organizations to make use of true collaborative learning environments that enable the involvement of large number of single/group participants (teachers, students, tutors among others) who can potentially belong to many different organizations, possibly situated at very different locations, and transparently share a huge variety of both software and hardware resources while enhancing humanto-human interaction (synchronously or asynchronously) through a friendly 3D-based user interface. Leveraging the inherent performance potential of Grid infrastructure for CSCL applications makes it possible to greatly enhance the collaboration between users in terms of both participant scalability (adding as many participants/groups as necessary) and resource availability (replicating and executing them in multiple Grid nodes) enabling collaboration as the most important learning method [14].

There are infrastructures that facilitate the sharing and exchange of learning objects via a dis- tribution learning Grid [6]. Such infrastructures define, among others, a range of services called Grid Learning Services (GLS), based on the OGSA (Open Grid Services Architecture) [59], and consisting of essential services in the education field, such as the services of e-qualification, collaboration and communication [55]. Further afield, some applications have been implemented to operate the Grid Learning Services in order to enable the members of a virtual community to create and distribute learning objects.

In the following sub paragraphs we present the advantages and the reasons for using Grid technology in collaborative learning systems:

- Computer supported collaborative learning applications are characterized by a high degree of user-user and user-system interaction and hence generate a huge amount of data usually collected in log files. In order to extract information useful to the group activity, these files must be processed in real time. Grid technology is used to process group activity log files and thus, makes it possible to provide timely feedback to users and compute different statistics [70].

- Educational institutions that cannot upgrade their computer software and hardware facilities can share other institutions' resources using Grid computing techniques. Although many institutions have adopted e-learning, the software and hardware facilities they use vary greatly [71]. This causes major difficulties in sharing teaching resources. Web service techniques enable the integration of different information systems within grids and solve this problem [30].

- CSCL applications require very short response time of queries submitted by the different actors. Indeed, a difficulty for the learner is to know about what and when he can contact the tutor at a learning session. As adviser, a misunderstanding of the learning activities does not always simplify his operations (in real time and appropriately). All these difficulties can cause problems of motivation of the learner or the tutor when he receives an important number of assistant requests from the learners.

- CSCL applications are inherently distributed, since students have to collaborate through 
networked computers, though we may distinguish cases in which students are collocated (and collaboration also happens face to face) and those in which collaboration is strictly carried through the computer [19]. Besides, CSCL applications may involve synchronous or asynchronous interactions, or a mixture of them [21]. For applications with these characteristics, the computational grid can offer an infrastructure that facilitates their deployment and enhances their performance.

- The large scale of the grid may allow the use of a high number of single/group participants collaborating within the CSCL application [10].

- Many CSCL applications have their users co-located, but others such as distance universities tools may have users spread along one country or even a larger area. Besides, the heterogeneous nature of grid shared resources may allow users to participate employing heterogeneous devices such as computers, PDAs or electronic black-boards, as well as data or software resources such as simulators or other domain packages [12].

- CSCL application can benefit from the transparent access feature of the Grid, since it eases some serious problems such as automatic application deployment and configuration that can be passed onto the grid scheduler. So, each actor of CSCL system can easily use the system and its features.

Finally, we can say that the complex, dynamic and modular nature of the CSCL field is especially motivating with respect to the use of Grid. Many Grid features can be adopted to be used by collaborative learning systems where the interactions are enormous and the treatment time is requested. Furthermore, CSCL applications call for some infrastructures that allow the use of heterogeneous distributed resources in a scalable manner on one hand and support all the activities of the actors in efficient manner on the other.

\section{COLEG Architecture}

The architecture of COLEG (which is a Gridbased collaborative learning system) can be expressed in three parts (see Figure 1). The right part shows the users of COLEG (learners, teachers (authors), tutors, and administrator). They can be connected to the Service Container from the portal to access services via their web browsers.

The left part presents the Learning Objects services (LO), supported by different contents creators (or content providers). The Learning Objects services can be physically located in different places or hosted in heterogeneous platforms. Each node containing the LO services represents a Virtual Organization (VO), which can have its own architecture, its own software, materials, and its organization policy. Each host has an operating system (which can differ from one host to another) and Globus Toolkit 4 [27] (GT4) as the Grid middleware.

In the center of the figure is the Service Container (or the Portal Server), which is the core of COLEG. It includes the following components:

a. The OGCE Portal: A Grid portal is a user's point of access to a Grid system [29, 32, 49]. It provides an environment where the user can access Grid resources and services, execute and monitor Grid applications, and collaborate with other users [36].

In our research, we opted for the OGCE (Open Grid Collaboration Environment) portal, which is an open source, a unified entry to the system, a mediator between the Grid and the users, and the development environment of the new portlets (services interface). It allows the authenticated users to profit from various services of learning, collaboration and communication and the various computing and storage resources.

In addition, OGCE allows developers to quickly develop and package web applications portlets [2], which can be implemented and administered in the portlets container. It is based on the Java Portlet model as implemented in CHEF [17]. OGCE is being deployed in a number of Grid portal projects including LEAD (Linked Environments for Atmospheric Discovery): a cyber infrastructure for mesoscale meteorology research and education [22], the NCSA alliance [57], the NSF Teragrid [66], and several other projects are evaluating it. The portlet concept, which is now a Java standard (JSR-168) [46], is simple. This is the same model that is used by the GridSphere portal framework [38] and the 


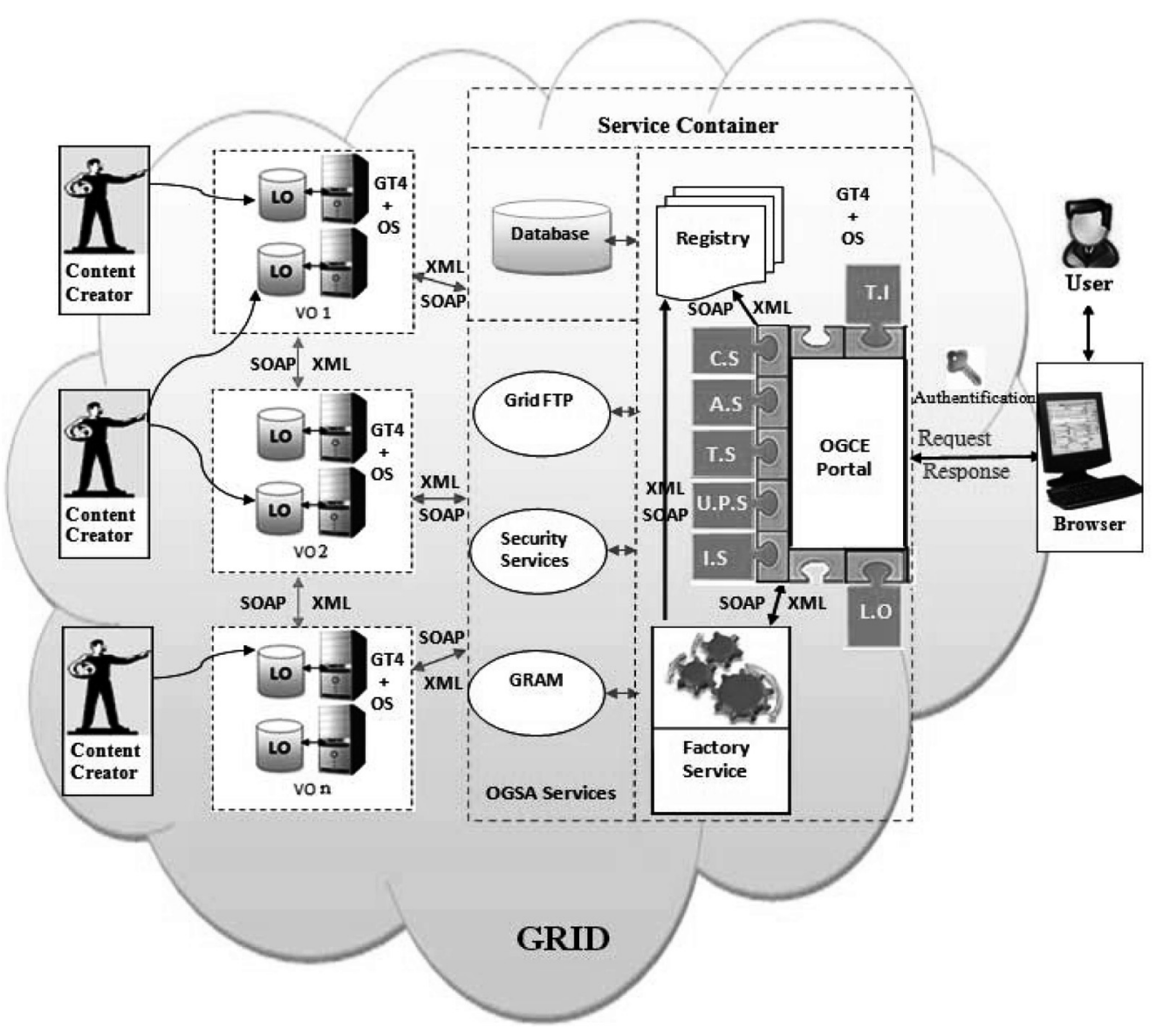

Figure 1. The general architecture of COLEG.

portals available from IBM, Sun, Oracle and BEA.

A portlet (the interface or the client of a Web Service [9]) is a component of the web server that owns a part of the portal display window. The portlet has access to the user's session state and the different portlets can communicate with each other through this mechanism.

A central concept in the architecture presented here is that the portal server provides two things:

1. A context to hold the user's session and the objects associated with that session. Some of these session objects come from the user's persistent state, which is also managed by the portal server, and some objects are created and used by portlets.

2. A container for portlets that are clients to remote Grid and web services. Portlet instances within this container share the user's context. Hence a portlet, which is a client to one service, has access to objects created in another service [35].
OGCE contains its own portlets, but it gives out to users the possibility to deploy new portlets. Among the standard OGCE portlets we can cite [58]:

- ProxyManager portlet: acts with MyProxy servers to search for user Proxy Credential to make them available to other components in the portal, to fetch the user's Grid proxy certificate from the MyProxy service and store it in the user's session. Any other portlet, which requires the user's proxy certificate in order to interact with a remote service on behalf of the user, can fetch the proxy from the session state. The ProxyManager will support multiple credentials, allowing the user to switch between community and user credentials, or to alternate between credentials for different Grids.

- Job Submission portlet: The GRAM (Globus Resource Allocation Manager) Job Submission Portlet enables users to submit batch jobs to remote resources via Globus GRAM. 
The portlet allows a user to specify job parameters, submit the job, and view job status information. This portlet requires a working GRAM server running on the remote resources with which the users will interact.

- The Generic Factory (GFac) portlet: can "wrap" any command-line application as an application service. An application service is a web service interface to a command-line application. When an application service is invoked with a given set of input parameters, it runs the application with those input parameters (possibly on a cluster of resources), monitors the application and returns the results to the user. This toolkit can be used by application providers (application service providers or service providers) to wrap any command-line application as an application service without writing any program code or modifying their applications in any way.

b. Portlets or Services of COLEG: Besides the standard portlets of OGCE, we can find the special own services of COLEG that are:

- Learning Objects management service (LO): it supports the management of learning objects: creation, update, search, personalization, etc. [42]. A learning object is any entity, digital or non-digital, which can be used, re-used and referenced during technology-supported learning [44]. These learning objects are placed in local repositories.

- Tools Integration service (TI): it allows the integration of sophisticated instruments (such as: simulators, microscopes, etc.) and various software tools (for example text editors, contents creation tools, etc.). Each tool is associated with a set of information describing how to integrate it.

- Collaboration Service (CS): it takes into account the collaborative process between the different actors of the environment. This service manages all data relating to various interactions as well as a set of tools to facilitate this process: synchronous collaboration tools (chat, whiteboard, videoconferencing...) and asynchronous (Forum, email, Wiki...).

- Awareness Service (AS): it allows a user to understand and measure the activity and the dynamics of the group where he is a member; to place his own action within the group, and thus coordinate his activities with those of others. This service uses a set of indicators for the various activities of learners, the rate of activity/inactivity, and the rate of participation of each member in the implementation of each task. It can also offer to different learners the perception tools (visualization) of the activities of other members (in a synchronous or asynchronous manner). In order to make this information useful to the group activity, it must be appropriately collected, classified and structured for later automatic processing by computers as part of a process of embedding information and knowledge into CSCL applications. The aim is to extract essential knowledge about the collaboration and to make it available to users as awareness and feedback [70].

- Traces Service (TS): it manages the traces from different actors. A trace in our context is a result of user interaction with the system [50]. The traces service offers ways to collect, analyze and interpret the traces left by various actors and in particular learners, as well as viewing their traces in various formats including graphics, statistics or mixed. Traces enable tutors and learners to be as aware as possible of the learning activity.

- Users Profile Service (UPS): So that our environment can take into account the different characteristics of learners when selecting the appropriate learning objects, COLEG provides a service that manages the profiles of learners. This service takes care of initializing the two profiles (cognitive and behavioral) of each new learner and their update. The later carried out at the end of various activities including: learning, assessment, collaboration, requesting assistance, etc. [41]. A User Profile is a source of knowledge, which includes acquisitions of all aspects of the user that may be useful for the conduct of the system.

- Indexing Service (IS): it allows extraction of information from a set of documents and organizing them in a way which makes it possible to reach them easily and quickly. Furthermore, Indexing Service of COLEG 
can extract both text and property information from files or any other pedagogical resource or material to facilitate efficient and rapid searching [41].

\section{c. OGSA Services:}

The OGSA (Open Grid Services Architecture) [59] is a computer service-oriented architecture, which ensures the interoperability of the heterogeneous systems so that various types of resources can communicate and share information. Among these services we can cite:

- GRAM(Globus Resource Allocation Manager): to facilitate the launch and control processes remotely in the form of execution requests in the same way as Remote Procedure Call (RPC) in client-server architecture. GRAM manages the resource (reservation, release) needed to services instances produced by services generators (factory). The instances are accessible through a dynamic link (handle) managed by a GRAM registry.

- GridFTP: is an extension of FTP for use with Grid computing. It is defined as part of Globus. The purpose of GridFTP is to provide a higher and more reliable file transfer performance for Grid applications. This is necessary because of greater demand for data transmission in the Grid (it is often necessary to transmit large files and this must be done quickly and safely).

- GSI (Grid Security Infrastructure): which performs the basic security functions (mutual authenticity certificates, trust, etc.).

d. Data base: It is used to record all the information useful for the operation of the system, namely: information on the actors, messages, appointments, traces, etc. [42].

e. Registry Service: centralizes the data concerning the deployed services, their sites and the policies controlling their use. It provides a central reference frame to obtain all information necessary to their localization and their use thanks to the integral assumption of the UDDI (Universal Description Discovery and Integration) specifications.

f. Factory Service [37]: is a tool which makes it possible to wrap a standard application with a web service so that it can be called from a portal. If we have an application installed as command-line which takes files as entries and produces files as outputs, we must only write one simple XML document, which describes our application (where to find it, the description of the entry necessary and the produced files of output) and the factory will transform this into web service able to launch instances of our application.

\subsection{Operation of COLEG}

The user wishing to interact with a Grid service of COLEG must locate it first. This user must perform a search from a directory by sending a query to the UDDI registry. Once the service is located, the user can access the WSDL (Web Service Description Language) document describing how to contact Grid Service Generator. The user is thus able to build a SOAP (Simple Object Access Protocol) message with the form specified in the WSDL document. After receiving a message from the user through the portal, the service generator dynamically creates instances of Grid service that will use the resource and release this resource at the end of life. The Grid service instances have internal states and can be created and destroyed dynamically. The generator then communicates to the user the GSH (Grid Service Handle) and the GSR (Grid Service Reference). The GSH is a unique service while the GSR is a WSDL document containing the information that a user must communicate with the service. Finally, the user begins a direct interaction with the instance of service under the format of a SOAP message.

\subsubsection{Scenario 1: Search for Learning Objects}

We face three scenarios regarding the availability of required service in the registry. The scenario where the service is available in the register is as follows (Figure 2):

- Firstly, the Learning Objects (LO) services must be published in the Registry (by the contents creators) and the learners must have Web browsers installed on their machines. Then, the learner connects to the portal and must authenticate himself by an authorized account (guaranteed by the security services of the Grid). 


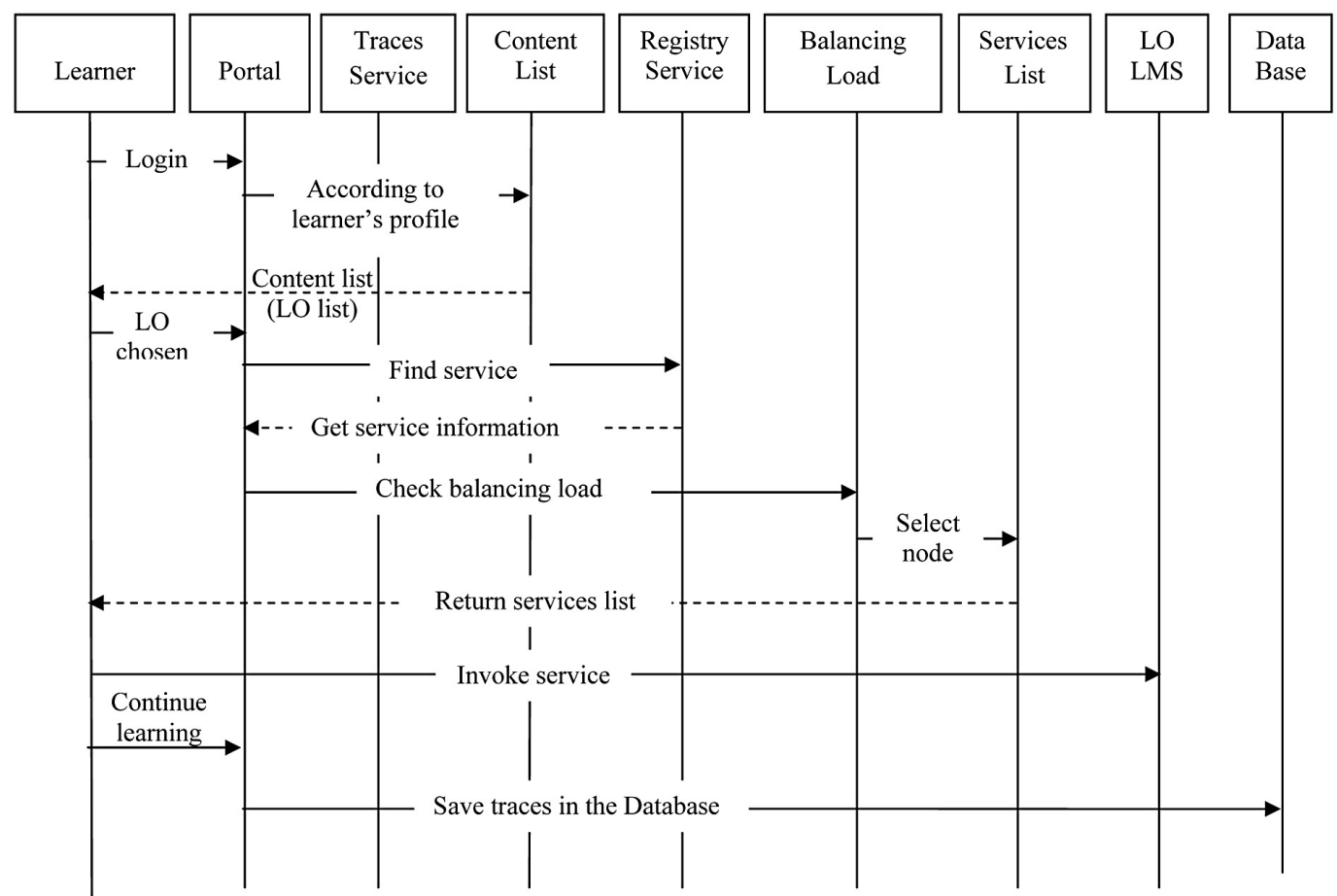

Figure 2. Sequence diagram concerning the search of the Learning Objects available in the Registry.

- The Portal will list all the learning objects (LO) available and diversify on the various nodes that correspond to the learner's profile. If the learner selects one of these LO (for example a course about Java) then the portal will discover the suitable service (LO) registered in the Registry according to metadata supported by the service.

- The registry will send information concerning the chosen contents (a WSDL document describing where the service is located, how to invoke it, the parameters required, etc.).

- The Portal will also check the load of nodes to choose the best place (node), - to optimize the use of the computation and data resources-; and to find where it will carry out the desired service using a Learning Management System (LMS).

- The learner can invoke the service; the portal itself will invoke the various services of the system automatically to support the needs of learner.

- Traces Service will record in the Database of the system all the events and all the notifications generated by the invocation of the various services.
Suppose now that the desired service is not available in the registry, but available in one node of the Grid (Figure 3):

- Learner asks the portal to find a LO (a course about "the operating systems", for example).

- The Portal will search for the required LO in the Registry.

- The service is not available in the registry; the Portal will send a request seeking the LO in all the available hosts in the Grid.

- If the LO is located, the Portal will ask the Factory Service sending it the necessary parameters to create a new instance of the service.

- When the Application Service (a component of the Factory) receives a request, it analyzes it, chooses the node where it's located and copies the data items remotely at the application host (using GridFTP).

- When the input data items are ready, the Application Service submits the job (with GRAM) to the application host. While using the results of the application, the Factory will create a SOAP message (answer) and will send it again to the Portal and will reg- 


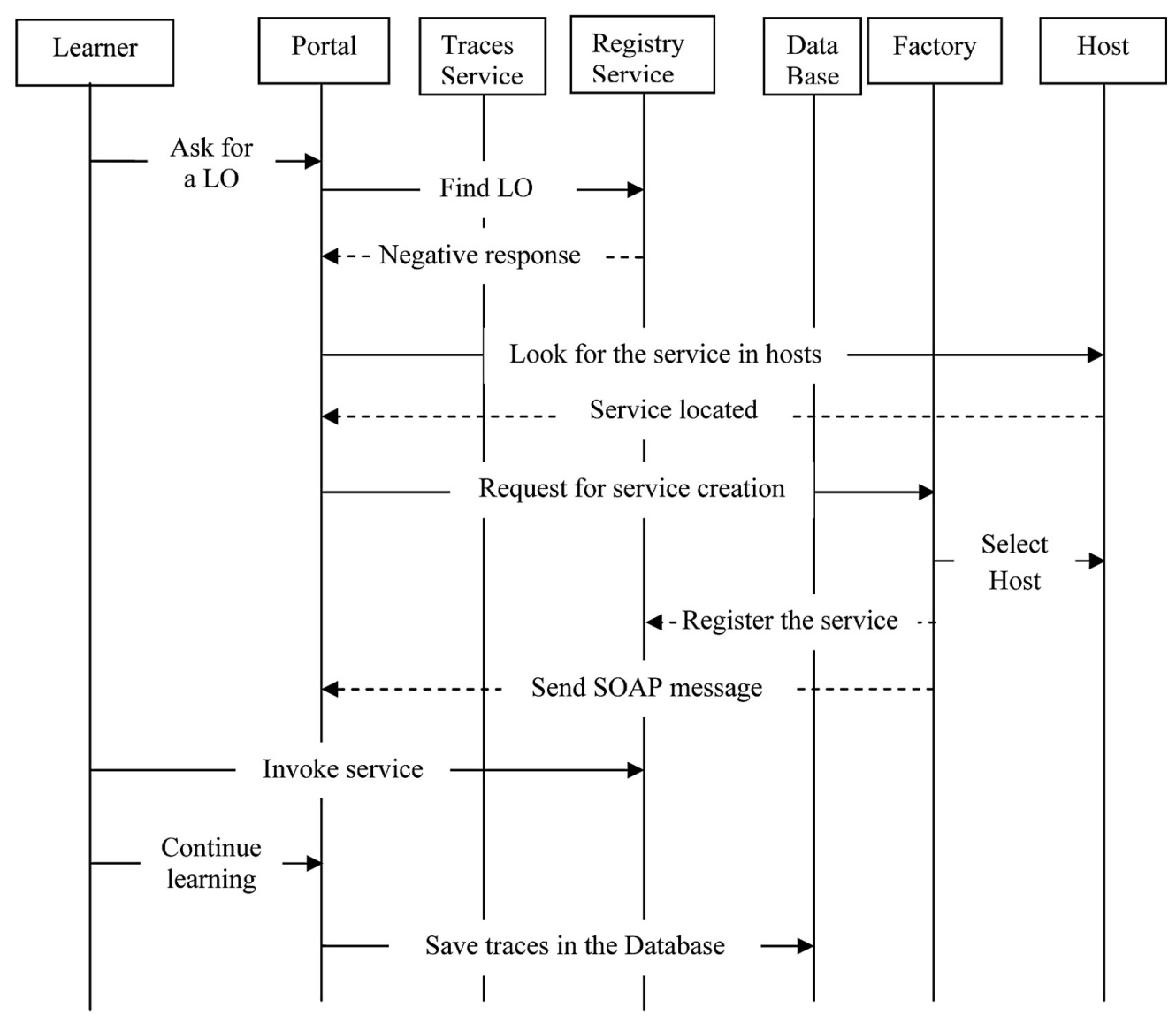

Figure 3. Sequence diagram concerning the search of the Learning Objects which are not available in the Registry, but in one node of the Grid.

ister the new instance of the service in the Registry.

- Learner can invoke the service and continue the learning process.

- The Traces Service will record in the Database of the system all the events and all the notifications generated by the invocation of the various services.

We suppose now that the service is neither available in the Registry nor deployed in one of the Grid nodes. In this case the system will react as follows (Figure 4):

- During the publication phase of the LO in the Registry, the Indexing Service indexes the Learning Objects and organizes them according to the contents, the author, the key words, etc.

- The Portal invokes the Indexing Service and extracts the learning objects that have the greatest frequency of appearance of the re- quired word ("operating systems" for example) according to an indexing method (for example TF-IDF [64]), and organizes them from the nearest to the farthest. Thus the choice of a LO is done by calculating the nearest distance between an available LO and the required $\mathrm{LO}$.

- The procedure is repeated until the moment when the distance exceeds a certain threshold.

- The Portal will send the chosen LOs to the learner, according to a decreasing relevance order.

- If the learner chooses a LO, the Portal will ask the Factory to create a new instance of the service, (according to the selected LO).

- Learner can now invoke the service and continue the learning.

- The Traces Service will record in the Database of the system all the events and all the noti- 


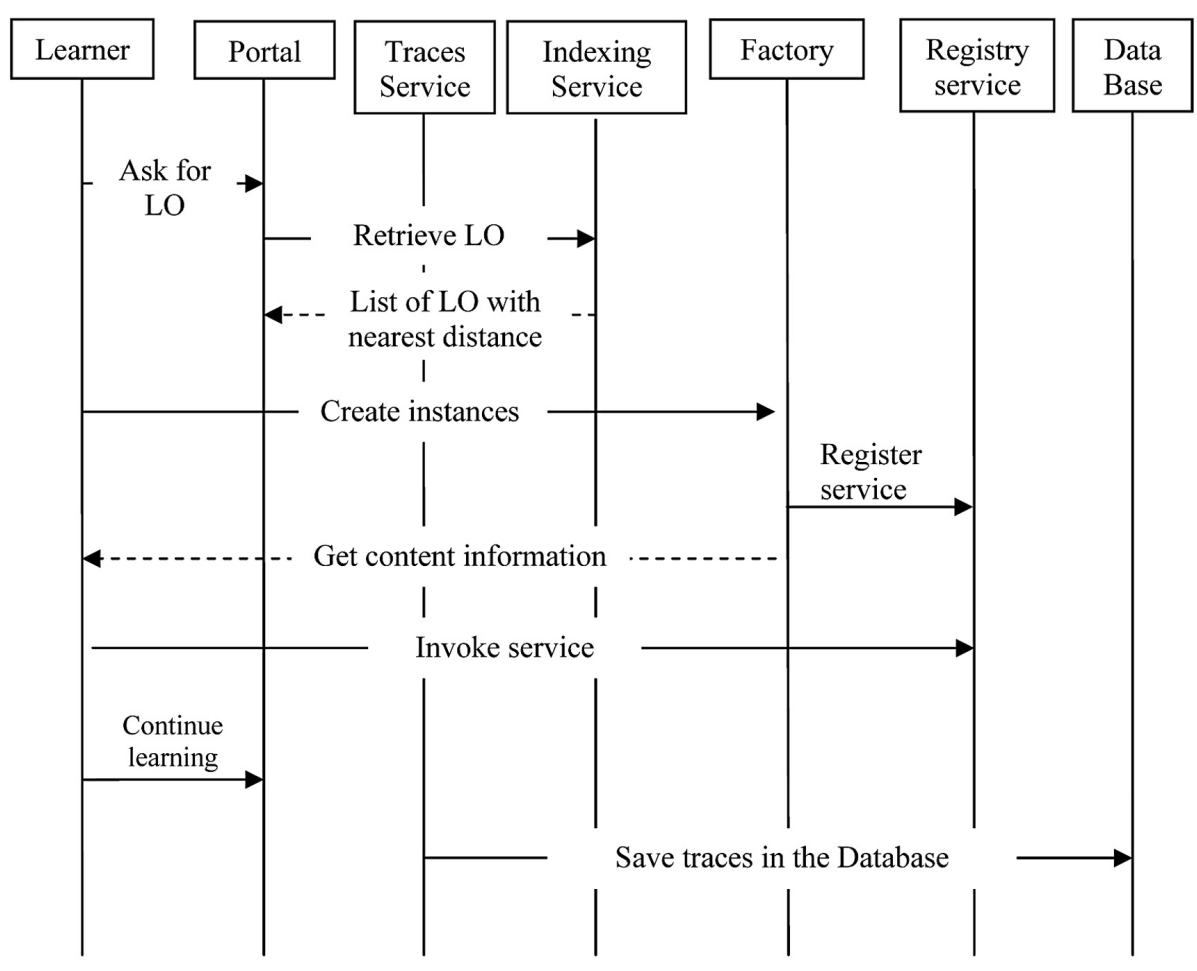

Figure 4. Sequence diagram concerning the search of the Learning Objects neither available in the Registry nor deployed in one of the Grid nodes.

fications generated by the invocation of the various services.

\subsubsection{Scenario 2: Communication with a Teacher}

The second scenario concerns the search for a teacher or author of learning objects. Indeed, our environment provides opportunities for learners to search for authors of specific learning objects. To illustrate the process, it is assumed that a learner wants to communicate with a teacher. We are facing two cases relating to the availability of a teacher during the time of the request establishment.

The scenario where the teacher is on line is as follows (Figure 5):

- Initially, the learner must recover the name of the author. It is guaranteed by the portal (when it provides to learner the wished learning object, it provides also its metadata: the name of the author, the key words, the creation date, etc.).

- The learner formulates a request seeking the teacher (the request includes: the name of the learner, the name of the teacher, the learning object and the communication tool that the learner wants to employ).

- The Portal will ask the Awareness Service (AS) and will check if the teacher is on line or not (the state of the teacher).

- The teacher is on line. The Awareness Service will provide to the portal all the necessary information concerning the teacher (the node where he is present, IP address of his machine, his operating system, etc.).

- The Portal will send an alert to the teacher informing him that a request for communication was carried out (the name of learner, the learning object and the communication tool).

- If the teacher is not yet ready to communicate, he can send a response of cancellation (we will see in the next scenario how the system will react in this case). If the teacher is ready to collaborate and he sees that the communication tool conforms to the communication situation, he sends his agreement 


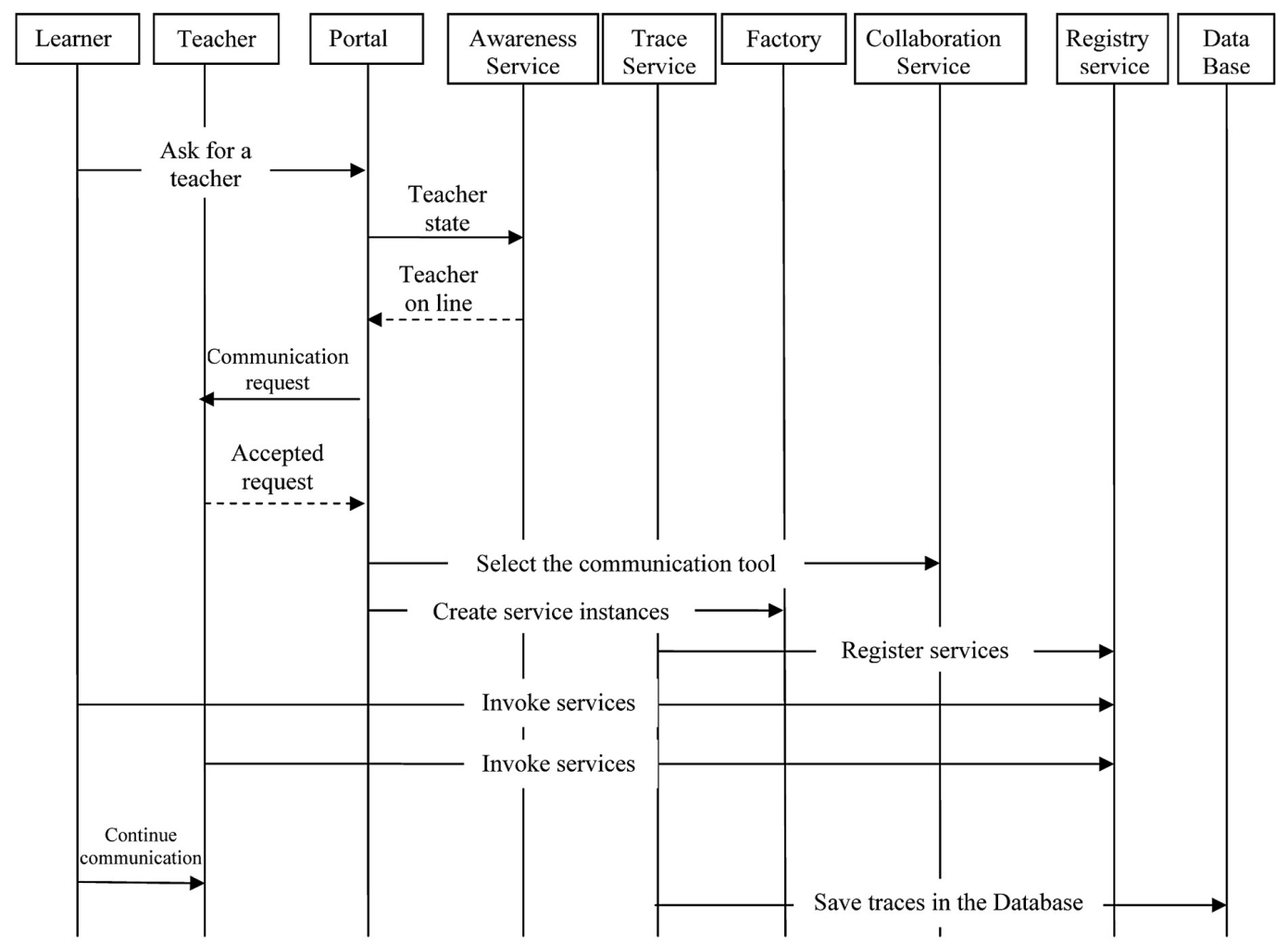

Figure 5. Sequence diagram concerning the communication of a learner with a teacher (the teacher is online).

(the teacher can propose another communication tool if the tool indicated by the learner is not suitable).

- The Portal receives the agreement of the teacher; it asks the Factory to instantiate the various services to use in the communication.

- The teacher and the learner can invoke the services and continue the communication.

- The Traces Service records in the Database all the generated events.

The teacher is not on line now; the system will react as follows (Figure 6):

- The learner asks the Portal to put him in communication with a teacher.

- The Portal will ask the Awareness Service to survey if the teacher is on line or not.

- The teacher is not on line. The portal will contact the User Profile Service, and will extract from the interest center of the desired teacher the subjects that he is interested in (for example the teacher is interested in the "Grid").
- After that, the Portal will send the recovered information to the Indexing Service, asking it to find the teachers who have common interests with the first teacher (the choice method of teachers is the same one discussed in scenario 1). For example, the Indexing Service gives as result two teachers: teacher 1 interested in "Globus" and teacher 2 in the "distributed systems". We take into account the relevance degree of the interest center of the teachers to order them.

- The Portal once again will ask the Awareness Service to survey if the two teachers indicated by the Indexing Service are on line or not.

- If teacher 1 is on line, he can (if he is ready) communicate with the learner as illustrated in previous scenario.

- If teacher 1 is not on line, the Portal will reformulate the request with teacher 2 and repeat the process.

- In the case where teacher 2 is not on line either again COLEG will solve this problem. It proposes to the learner to send a 


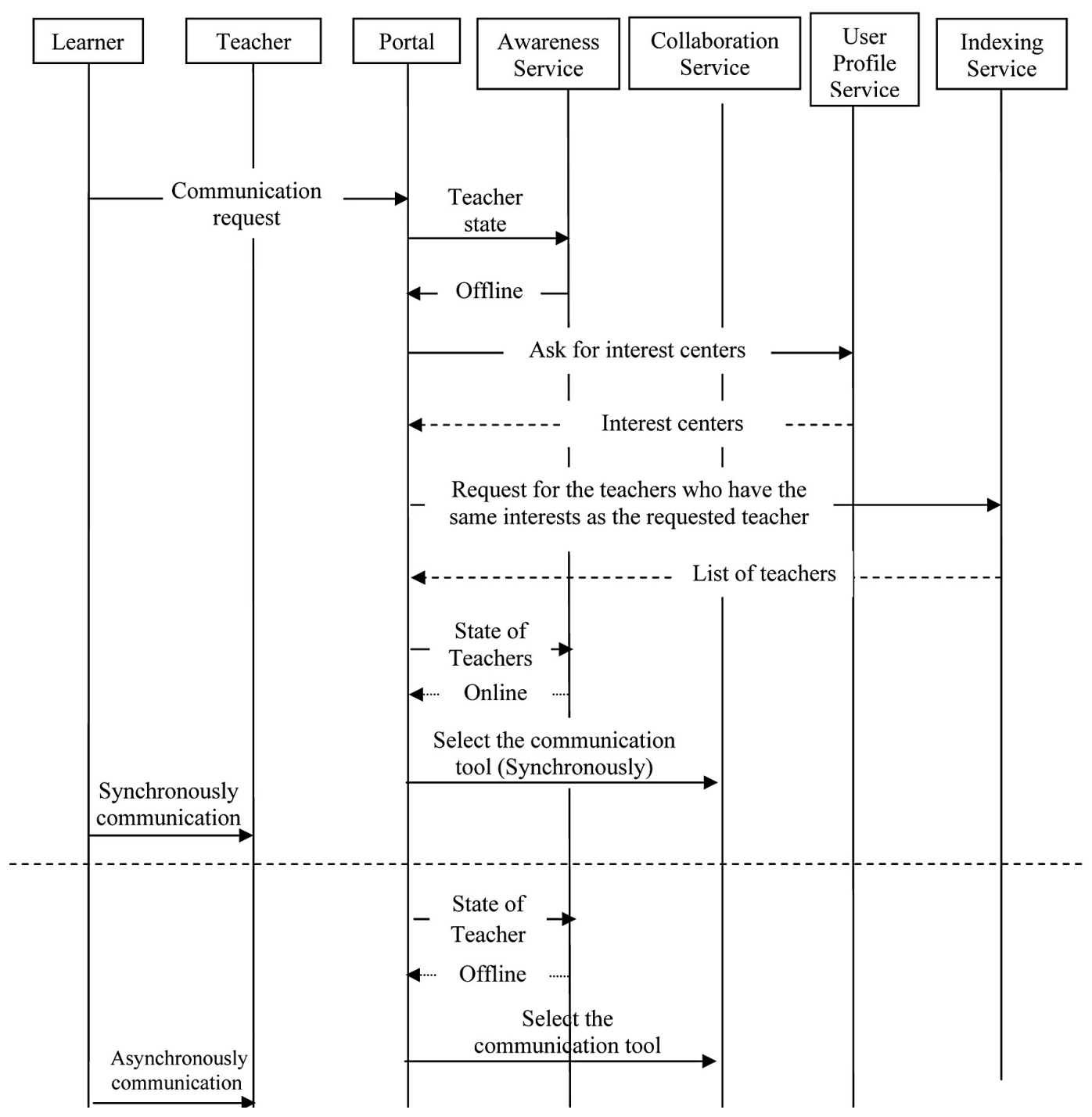

Figure 6. Sequence diagram concerning the communication of a learner with a teacher (the teacher is offline).

mail, or to fix an appointment with the desired teacher at the beginning of the learning situation (by using the asynchronous communication tools).

- If the learner approved, the portal will ask the Factory to instantiate the appropriate services to the learner choices (for example instantiate the Calendar service to fix the appointment).

- Always the Trace Service records in the Database all the generated events.

\subsection{Implementation}

COLEG has a modular architecture based on the OGSA model and receives the benefits of the Grid expressed in storage capacity and calculation provided by the Globus Toolkit. The Globus middleware is often the basis of the architecture on which the Grids are built.

The core of COLEG is the OGCE portlet container, which is a free software (open source) used to develop Grid applications. OGCE can be used to quickly develop and package the web applications portlet (or services), which may be implemented and administered in the portlets container. So, to run COLEG, we installed the Globus Toolkit as Grid middleware, on the Grid layer we installed the OGCE portal where we will deploy our various services as portlets conforming to those of OGCE. We have deployed under the OGCE a set of Sakai portlets. For 
the collaboration tools, we have adopted Agora Lancaster, which is an online communication tool, open source, very simple to use (see Figure 7 for more details).

Our contributions concern the use of OGCE portal with Sakai on one hand and the facility of integrating the proposed services into COLEG on the other (by using Java language, we have developed a system that facilitates the adoption of these services into the grid portal). In fact, any user can easily apply any service of COLEG through the OGCE portal at any moment and from anywhere.

Many software tools are used for implementing COLEG, such as: Java, Ant $1.6+, \mathrm{C}++$ compiler, Perl 5.005, JDBC, etc.

In the appendix, we present some screenshots of COLEG, which were developed in the LAIG laboratory at the University of Guelma. So far, we have implemented some services, including the learning objects management, the traces services and the collaboration services.

Figure 9 shows the configuration of the OGCE portlets as well as those of COLEG. In Figure

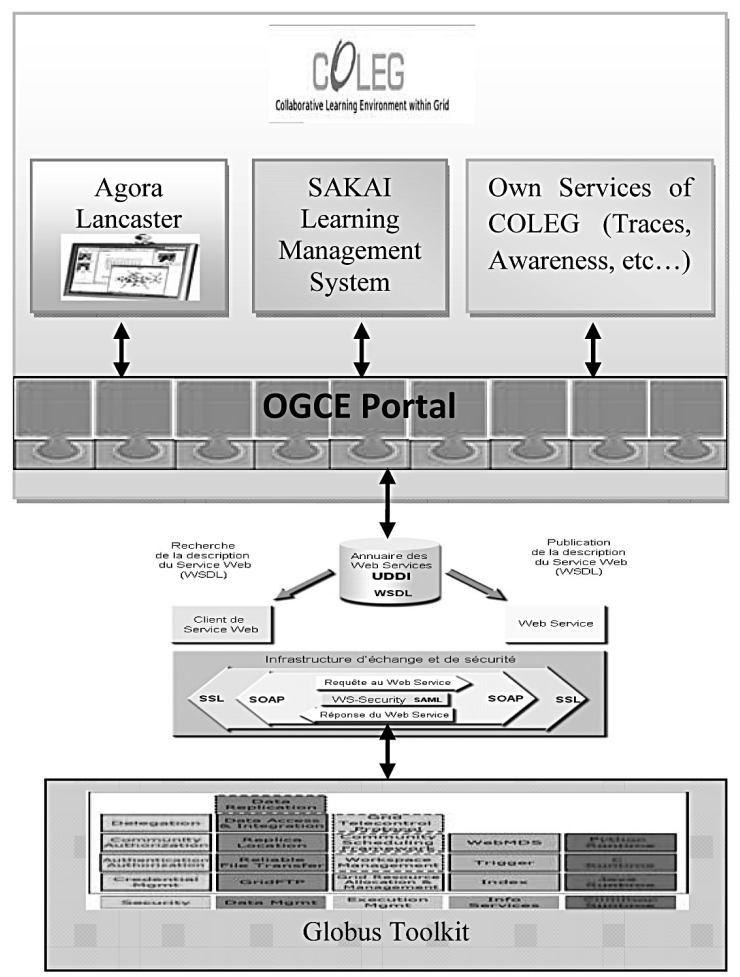

Figure 7. Technique description of tools and software used in COLEG implementation.
10 , we show the ability to transfer files within COLEG. Figure 11 shows a user friendly interface to use Learning Objects (LO).

\section{Related Works}

Today, there are many contributions in the field of Grid Computing where the goal is implementation of the environments aiming to facilitate the collaborative learning. Below we present some related works and a comparative study between these various works. The purpose of this study is to demonstrate the value of our contribution over existing ones.

\subsection{E-learning/CSCL Projects Based on Grid Technology}

The first system to cite is GridCole, which is a collaborative learning system that allows teachers to specify the situation to be supported by the system in terms of the sequence of activities to be performed by participants and the tools and the documents that will be used in each activity. Such tools are integrated by the system according to the "tailoring by soft integration" model, so that they can be employed by participants in order to perform the activities included in the situation. Besides, GridCole supports scripted collaborative learning. More specifically, the system is able to interpret collaboration scripts described with the IMS-LD (Instructional Management Systems- Learning Design) specifications. This enables GridCole to guide the participants of collaborative learning situations by determining the activity that should be performed by each one of them according to the collaboration script. It is also worth mentioning that GridCole system can be employed to support the realization of situations in which participants collaborate either face-toface or remotely and situations in which collaboration is either synchronous or asynchronous [11].

Another system which supports the collaboration over the Grid is GESOTC (Grid Environment for Sharing Objects). This last one is a collaboration platform based on Grid Learning Services (GLS) [6]. It allows the microscopic entities (i.e. students and teachers) of the same community to gather, thanks to the services of 
the GLS to share the learning resources [23]. It brings a solution to the problem, which is here of a macroscopic nature (between the communities), by accentuating the exchanges between the learning communities and thus includes the microscopic proposals, which are for its only services. The basic architecture of GESOTC is primarily made up of three layers: a Grid Middleware layer, a GLS layer and an LMS layer [6].

Concerning sharing data process, we can cite AstroGrid. It is a project aiming at producing more economic, faster and effective astronomy through the generation of open standards and interfaces. The AstroGrid framework helps to enable different data centers across the United Kingdom to publish services and data into a data-grid infrastructure accessible on the Web. Such a framework also makes it easier for the different astronomical data centers to interact; it offers a wide range of analysis and visualization tools through a common interface [18].

AstroGrid has a modular architecture, open to all contributions from data, services or resources (it is made up of a set of layers).

Furthermore, ULabGrid is an infrastructure to develop distant laboratories for undergrad students over a Grid. It has a new architecture that allows the educators to design remote collaborative laboratories for university students using the Grid infrastructure [5]. This project is one of the first in its type in trying to combine the facilities that Grid provides in a practical scenario in order to achieve resource sharing and motivate collaborative work. In this sense, the design of Grid-based collaborative learning scenarios should be supported by semantic descriptions that allow the best tracking of resources available in the network [16]. In ULabGrid, the users are capable to run tools remotely from everywhere at any time using their own computers.

Another system, which used the ontology principles for supporting the learning process over the Grid is OntoEdu (Ontology-based Education Grid System for e -Learning) [39]. It is a flexible platform for online learning which is based on diverse technologies like ubiquitous computing, ontology engineering, Web semantics and computational Grid. It is compound of five parts: user adaptation, automatic composition, educative ontologies, a module of services and a module of contents; among these parts the educative ontology is the main one. The main objectives of OntoEdu are to obtain reusability of concepts, adaptability for users and devices, automatic composition, as well as scalability in functionality and performance.

With the use of the ontology, OntoEdu can "learn" knowledge from education specialists and then automatically composes specific service system in terms of user requests which is called automatic composition.

Finally, the Advanced Knowledge Technologies (AKT) interdisciplinary research collaboration is a project to develop knowledge management technologies, funded by the UK's Engineering and Physical Sciences Research Council (EPSRC). The related CoAKTinG (Collaborative Advanced Knowledge Technologies in the Grid) project, funded as part of the UK's eScience Initiative on Grid computing, aims to integrate and adapt AKT and related technologies specifically to support distributed scientific collaboration. As part of the AKT project's conception of the convergence of knowledge technologies and grid computing as the Semantic Grid. CoAKTinG provides tools to assist scientific collaboration by integrating intelligent meeting spaces, ontologically annotated media streams from online meetings, decision rationale and group memory capture, meeting facilitation, issue handling, planning and coordination support, constraint satisfaction, and instant messaging/presence [13].

There are other systems cited in the literature. We can mention, according to [16]: the Grid Service Based Portal for Virtual Learning Campus [65], the Generic Engineering Framework for Technology Enhanced Learning (TEL) Embracing the Semantic Web [54], the AgentBased Collaborative Virtual Environment for technology enhanced learning in the Service Grid [43], KGTutor, a Knowledge Grid Based Intelligent Tutoring System [73], LAGrid, a Learning Assessment Grid [40], the KnowledgeGrid-Based Cooperative Learning Environment [74] and SELF, a Semantic Grid-based E-Learning Framework [1]. The reader can consult [16] and [20] for more details about these projects and other systems. 


\subsection{Comparative Study}

We presented in the previous paragraphs some e-learning systems or projects based on grid technology. In order to know the impact of our environment, we conducted a comparative study between the aforementioned environments and COLEG. We have taken into account as criteria the various services offered by each of these environments/systems as well as other characteristics (see Figure 8).

We note that a certain number of services are not taken into account by the previous environments/projects/systems. We cite: the virtual organizations management, the resources indexing and the group awareness. These services are taken into account by our environment COLEG.

\section{Conclusion}

A Grid is an environment which allows the sharing of resources (computers, disk space, memory, bandwidth, data, instruments such as tele-

\begin{tabular}{|c|c|c|c|c|c|c|c|}
\hline $\begin{array}{l}\text { Platforms/Systems } \\
\text { Services \& } \\
\text { Characteristics }\end{array}$ & $\begin{array}{l}\frac{0}{0} \\
0 \\
0 \\
0 \\
0 \\
0\end{array}$ & $\begin{array}{l}\cup \\
\stackrel{5}{0} \\
\mathscr{\omega} \\
\text { ஸी }\end{array}$ & 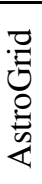 & 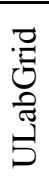 & 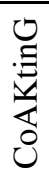 & 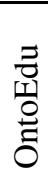 & $\begin{array}{l}0 \\
0 \\
0 \\
0\end{array}$ \\
\hline Adaptability & $x$ & $\times$ & $\times$ & & $x$ & $x$ & $x$ \\
\hline $\begin{array}{l}\text { Instruments (or tools) } \\
\text { integration }\end{array}$ & $\times$ & & $\times$ & $\times$ & & & $\times$ \\
\hline Use of an LMS & $x$ & $\times$ & & & & & $\times$ \\
\hline Learning Traces service & & $\times$ & & & $x$ & & $x$ \\
\hline $\begin{array}{l}\text { Virtual Organizations } \\
\text { Management }\end{array}$ & & & & & & & $\times$ \\
\hline Collaboration Services & $x$ & & $x$ & & $x$ & & $x$ \\
\hline $\begin{array}{l}\text { Learning Objects } \\
\text { Management }\end{array}$ & $\times$ & & & & & & $\times$ \\
\hline Use of Portal & $x$ & & $x$ & $x$ & & & $x$ \\
\hline $\begin{array}{l}\text { Build on Grid } \\
\text { Learning Services }\end{array}$ & & $\times$ & & & & & $\times$ \\
\hline Use on Ontology & & $x$ & & & $x$ & $x$ & \\
\hline Use of Workflow & & & $x$ & & & & \\
\hline Resources indexing & & & & & & & $x$ \\
\hline Group awareness service & & & & & & & $x$ \\
\hline
\end{tabular}

Figure 8. Comparative study between learning Grid environments/systems. scopes or microscopes, etc.) that are connected to a network (e.g. the Internet) [34].

Emerging technologies based on the Grid are increasingly adopted to improve education and provide better services for learning. This is marked around the world by developing widely distributed tutorials systems. Learners, regardless of their computer systems, can access shared knowledge on distributed sites [72]. They can collaborate to improve their cognitive and social skills. A set of services are offered to various actors to facilitate their tasks in the environment.

Furthermore, Grid technology provides a set of interesting features which represent an ideal context for supporting and producing major benefits for CSCL applications [4,24]. Such important features include: large scale of Grid infrastructures, wide geographical distribution of resources, multiple administrations from different organizations, transparent and dependable access as well as the capability of granting access to shared, heterogeneous resources in very dynamic environments [10].

In the context of collaborative learning, these services cover the activities of learning, assessment, collaboration, mentoring, etc. We noticed that the services developed by other environments or projects are not standard. After studying a number of systems/environments built on the Grid infrastructure, we found that some services are missing. These services are taken into account by our environment COLEG. Indeed, this collaborative learning environment based on Grid has a set of services to eliminate problems in the current CSCL environments. We have proposed new services including: group awareness, resources indexing, management of user profiles and traces of learning.

COLEG aims to improve the learning, facilitates collaboration, communication and provides another dimension of adaptability and flexibility through the use of Grid technology. It allows the integration of tools offered by providers within the context of a service-oriented computational Grid in order to support the realization of collaborative learning situations. COLEG provides work and/or learning space flexible and adaptive, guaranteed by its modular architecture, which is based on OGSA. In fact, the user may at any time and from anywhere integrate tools and services he finds appropriate to 
his learning without the need for intervention by administrators or technical persons.

In addition, COLEG aims at providing the best equipment and tools for better conduct of the learning situation from the possibility:

- to work with both synchronous and asynchronous modes provided by collaboration services,

- to be as aware as possible of what is happening in the work space, guaranteed by the group awareness service,

- to take into account the knowledge and behavior of learners through the profile management service, and

- to keep all actions performed by learners through the traces service.
COLEG does not provide only the possibility to provide at the user's request the services available in the registry, but it exceeds it by the automatic and dynamic services creation from other services according to the need expressed by the users, using the Factory services.

Finally, COLEG is implemented in the University of Guelma. We have already implemented the majority of services and we expect in the future to conduct an experiment with a sample of university students.

\section{Appendix}

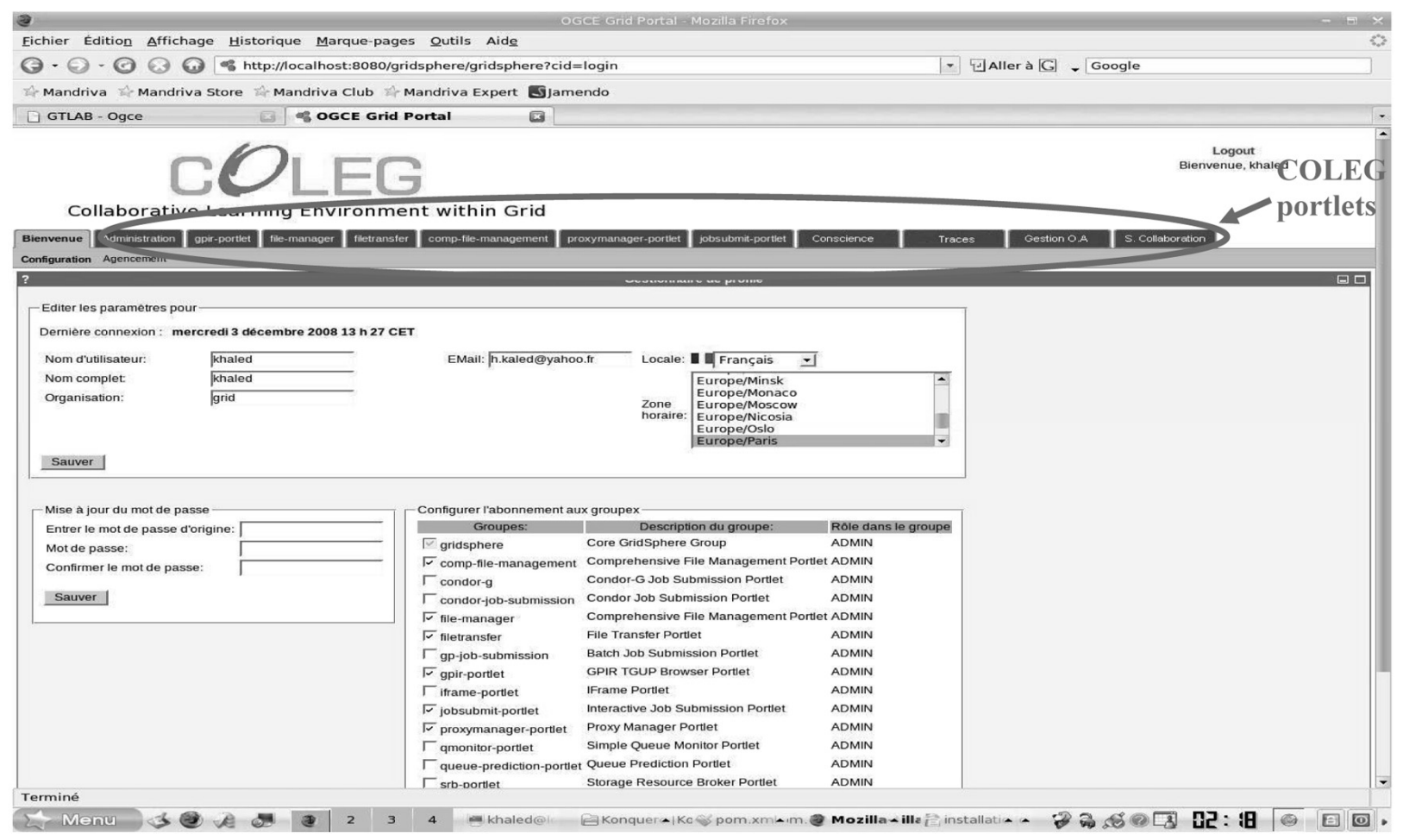

Figure 9. Portlets configuration. 


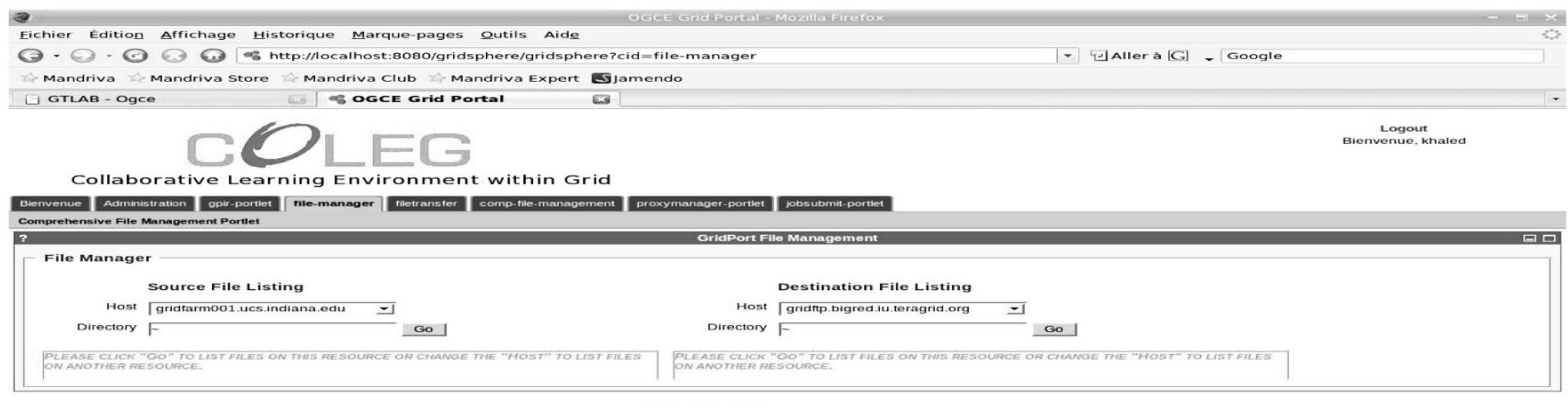

Terminé

Figure 10. Files transfer in COLEG.

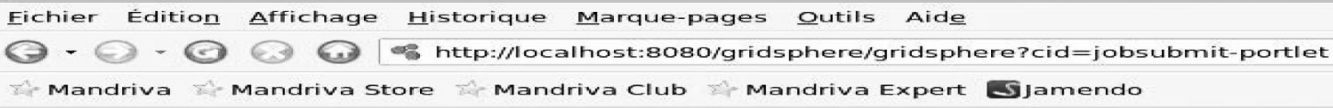

$\longrightarrow$

Collaborative Learning Environment within Grid

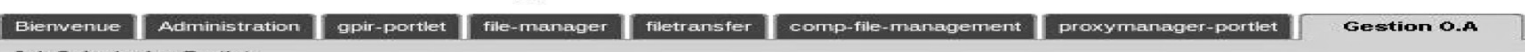
Job Submission Portlet Gestion des objets diappremtissage

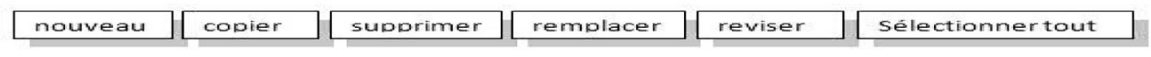

Emplacement: Poste 02

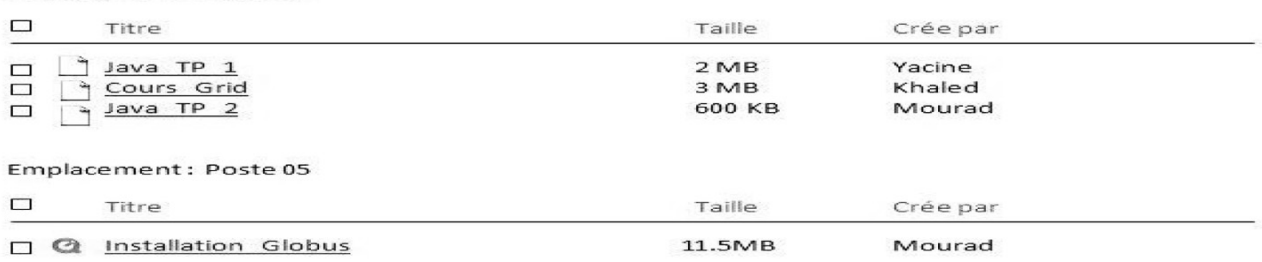

Figure 11. Interface for the LO management service. 


\section{References}

[1] Z. AbBAs, M. UMER, M. ODEH, R. MCClatchey, A. ALI, F. AHMAD, A Semantic Grid-based E-Learning Framework (SELF). In Collaborative and Learning Applications on Grid Technology (CLAG), 5th International Symposium on Cluster Computing and Grid, Cardiff, Wales, UK, May 2005.

[2] A. Abdelnur, E. ChiEn, S. HepPer, (EDS.), Portlet Specification 1.0. Java Community Process Program, 2003. Available from http://jcp.org/en/home/index

[3] C. Allison, S. A. Cerri, P. Ritrovato, A. Gaeta, M. GAETA, Services, Semantics and Standards: Elements of a Learning Grid Infrastructure. Applied Artificial Intelligence Journal, Special issue on Learning Grid Services, 19(9-10), pp. 861-879, 2005.

[4] K. Amin, S. Nijsure, G. Laszevski, Open Collaborative Grid Services Architecture (OCGSA). In Proceedings of the W3C EuroWeb 2002 Conference, Oxford, UK, 2002.

[5] O. ARDAIZ, ET AL. ULabGrid, an infrastructure to develop distant laboratories for undergrad students over a Grid. 1st European Across Grids Conference, Universidad de Santiago de Compostela, Spain, 2003.

[6] B. BATChaKui, C. TANGHA, G. EdOUARD, Environnement de collaboration basé sur le Grid Learning Services (GLS) pour les communautés de formation à centre d'intérêt commun. 4th Annual Scientific Conference of the Research Network LORNET, UQAM, Montreal, Canada, November 4-7, 2007.

[7] F. BERMAN, G. FOX, T. HEY, Grid computing: Making the global infrastructure a reality. Wiley Series in Communications, Networking and Distributed Systems, Wiley: Chichester, 2003.

[8] R. BJorson, A. SHERMAn, Grid computing and the Linda Programming Model. Dr. Dobb's Journal, September 2004. Available from: http://www.ddj .com/184405800

[9] D. BoOth, H. HaAs, F. McCabe, E. Newcomer, M. Champion, C. FERris, D. OrChard, Web Service Architecture. W3C Working Group Note, February, 2004. Available from:

http://www.w3c.org/TR/ws-arch

[10] M. L. Bote-Lorenzo, Y. A. Dimitriadis, E. GóMEZ-SÁNCHEZ, Grid Characteristics and Uses: a Grid Definition. Proceedings of the 1st European Across Grids Conference (CD), Santiago de Compostela, Spain, 2003.

[11] M. L. Bote-Lorenzo, ET AL. Gridcole: A tailorable grid service based system that supports scripted collaborative learning. Computers \& Education, 51(1), 2008.
[12] M. L. Bote-Lorenzo, ET AL. Towards reusability and tailorability in collaborative learning systems using IMS-LD and Grid services. International Journal on Advanced Technology for Learning, 1(3), pp. 129-138, 2004.

[13] S. BucKingham-Shum, D. De Roure, M. EISENStadt, N. Shadbolt, A. TATE, CoAKTinG: Collaborative Advanced Knowledge Technologies in the Grid. Proceedings of Second Workshop on Advanced Collaborative, Eleventh IEEE Int. Symposium on High Performance Distributed Computing (HPDC-11), Edinburgh, July 24-26, 2002.

[14] S. Caballé, F. Xhafa, T. Daradoumis, J. MARQUÈS, Towards a Generic Platform for developing CSCL Applications Using Grid Infrastructure. In Proceedings of the 1st International Workshop on Collaborative Learning Applications of Grid Technology (CLAG), Chicago, Illinois, 2004.

[15] N. Capuano, A. Gaeta, G. Laria, F. Orciuoli, P. RITROVATO, How To Use GRID Technology for Building the Next Generation Learning Environments. 2nd International LeGE-WG Workshop on e-Learning and Grid Technologies: a fundamental challenge for Europe, Paris, France, 2003.

[16] N. Capuano, M. Gaeta, P. Ritrovato, The Anatomy of the Learning Grid. In: Salerno, S., Gaeta, M., Ritrovato, P., Capuano, N., Orciouli, F., Miranda, S., Pierri, A. (eds.) The Learning Grid Handbook, Concepts, Technologies and Applications. The Future of Learning, 2, pp. 3-19, IOS Press, Amsterdam, 2008.

[17] CHEF PROJECT, http://chefproject.org/chef/portal

[18] P. Contreras, F. Murtagh, AstroGrid as an eLearning Environment. 1st International Kaleidoscope Learning Grid SIG, Workshop on Distributed e-Learning Environments, Vico Equense, Naples, Italy, 2005.

[19] C. CROOK, Computers and the Collaborative Experience of Learning. Routeledge, London, UK, 1994.

[20] A. DARADOUMIS, State of the Art on Learning Grid: Technological Perspective. In Learning Grid: a newsletter from the Kaleidoscope Learning Grid $S I G$, N. Capuano ed., N. 10, pp. 4-6, December 2006.

[21] P. Dillenbourg, Collaborative Learning: cognitive and computational approaches. Oxford, UK, Elsevier Science, 1999.

[22] K. DROEGEMEIER, ET AL. Linked Environments for Atmospheric Discovery (LEAD): A Cyber Infrastructure for Mesoscale Meteorology Research and Education. 20th International Conference on Interactive Information and Processing Systems (IIPS) for Meteorology, Oceanography, and Hydrology, The 84th AMS Annual Meeting, Seattle, WA, 2004.

[23] P. DugENIE, Orientation et usage de l'architecture de services Grille OGSA. Manifestation des Jeunes Chercheurs francophones dans les domaines des STIC (MajecStic'2005), Rennes, France, 2005. 
[24] I. Foster, Computational grids. In: The Grid: blueprint for a future computing infrastructure, eds. Foster, I. Kesselman, C. San Francisco, CA, USA: Morgan Kaufmann, pp. 15-52, 1998.

[25] I. FOSTER, The grid: a new infrastructure for $21 \mathrm{st}$ century science. Physics Today, 55, pp. 42-47, 2002.

[26] I. FOSTER, What is the grid? A three point checklist. GRIDSTART technical newsletter, March 2003.

[27] I. FOSTER, Globus Toolkit Version 4: Software for Service-Oriented Systems. In: IFIP International Conference on Network and Parallel Computing, Springer, Heidelberg, 2005.

[28] I. Foster, C. Kesselman, Computational grids: Chapter 2, in The Grid: Blueprint for a New Computing Infrastructure. Morgan-Kaufman, 1999.

[29] I. Foster, C. Kesselman, The Grid2: Blueprint for a New Computing Infrastructure. Ian Foster and Carl Kesselman (Eds.), Morgan-Kaufman, 2004.

[30] I. Foster, C. Kesselman, S. Tuecke, The anatomy of the grid enabling scalable virtual organizations. International Journal of Supercomputer Applications, 15, pp. 200-222, 2001.

[31] G. Fox, Education and the Enterprise With the Grid. In: Berman, F., Fox, G., Hey, A. (eds.): Grid Computing: Making the Global Infrastructure a Reality. John Wiley \& Sons, Chichester, UK, pp. 963-976, 2003.

[32] G. FoX, F. BERMAN, T. HEY, Grid Computing: Making the Global Infrastructure a Reality. Fox, G. (Eds.), Wiley, 2003.

[33] M. GAETA, P. Ritrovato, S. SALERnO, Implementing new advanced learning scenarios through grid technologies. Proceedings of 1 st LeGE-WG International Workshop on Educational Models for GRID Based Services, Lausanne, Switzerland, 2002. http://ewic.bcs.org/conferences/2002/ 1stlege/session1/paper3.htm

[34] A. Gallardo, L. Diaz de Cerio, K. Sanjeevan, HGRID: A Self-configuring Grid Resource Discovery. Journal of Computing and Information Technology (CIT), 16(4), pp. 333-338, 2008.

[35] D. GAnNon, ET AL. Building Grid Portal Applications From a Web Service Component Architecture. Proceedings of the IEEE, 93(3), pp. 551-563, 2005.

[36] D. GANNON, ET AL. Building Grid Services for User Portals. In GGF Workshop on Designing and Building Grid Services, Chicago, 2003.

[37] GENERIC FACTORY (GFAC), http: //www . collabogce.org/ogce/index.php/GFAC

[38] GRIDSPHERE PORTAL, http://www.gridsphere.org

[39] C. Guangzuo, C. Fei, C. Hu, L. Shufang, OntoEdu: a case study of ontology-based education grid system for e-Learning. In: GCCCE2004 International conference, Hong Kong, 2004.
[40] W. Guiling, L. YuShun, Y. ShengWen, M. ChunYu, X. Jun, S. MeILIN, Service-oriented Grid Architecture and Middleware Technologies for Collaborative e-Learning. Proceedings of the 2005 IEEE Conference on Services Computing (SCC'05), IEEE, Orlando, Florida, USA, July 11-15, 2005.

[41] K. HALIMI, Architecture d'un système d'apprentissage collaboratif à base de Grid. Magister Thesis, Computer science department, Guelma University, Algeria, 2009.

[42] K. Halimi, Y. LAFIFI, M. HAdJERIS, COLEG: environnement de CSCL à base de GRID. International conference: EACP'08 (Environnements d'Apprentissage pour les Communautés de Pratique), University of Tlemcen, November 18-20, Tlemcen, Algeria, 2008.

[43] C. Huang, F. Xu, X. Xu, X. Zheng, Towards an Agent-based Robust Collaborative Virtual Environment for e-Learning in the Service Grid. In Lecture Notes in Computer Science, Springer, 4088, pp. 702-707, 2006.

[44] IEEE 1484.12.1, Learning Technology Standards Committee. Learning Object Metadata standard, Draft Standard for Learning Object Metadata, 2002. http://ltsc. ieee.org/wg12/index.html

[45] R.-T. Johnson, D.-W. JOHnson, An overview of cooperative learning. In J. S. Thousand, A. Villa, A. Nevin (Eds.), Creativity and collaborative learning: a practical guide to empowering students and teachers, Baltimore, MD, USA: Brookes Press, pp. 31-44, 1994.

[46] JSR-168 PORTLET SPECIFICATION. http://www . jcp.org/aboutJava/communityprocess/final/jsr168/

[47] H. KASH, M. REZA-RAZZAZI, A distributed service oriented e-Learning environment based on grid technology. Proceedings of the Saudi 18th National Computer Conference, (NCC18), Riyadh, Saudi Arabia, March 26-29, 2006.

[48] T. KoshMANn, CSCL: Theory and practice of an emerging paradigm. Malwah, NJ, USA, Lawrence Erlbaum, 1996.

[49] S. KRISHNAN, ET AL. The XCAT Science Portal. Proceedings of Super computing 2001, November, Denver, 2001.

[50] Y. Lafifi, K. Halimi, A. Ghodbani, N. SAlhi, Learners Monitoring Based on Traces in CSCL System. INFOCOMP: Journal of Computer Science, 8(2), pp. 61-72, 2009.

[51] Y. LI, S. YANG, J. JIANG, M. SHI, Build grid-enabled large-scale collaboration environment in e-Learning grid. Expert Systems with Applications, 31, pp. 742754, 2006.

[52] C. J. LiAO, The collaboration of learning objects in a grid environment. IEEE Learning Technology, 6, pp. 19-22, 2004. 
[53] C. J. LiaO, F.-C. OU Yang, K. Chincheng-Hsu, A Service-oriented Approach for the Pervasive Learning Grid. Journal of Information Science and Engineering, 21, pp. 959-971, 2005.

[54] J. LischKa, D. Karagiannis, A Generic eLearning Engineering Framework Embracing the Semantic Web. In Lecture Notes in Computer Science, Springer, 3192, pp. 341-350, 2004.

[55] A. Mirelle, R. NKAMBOU, Les services de collaboration à travers la grille d'apprentissage. M.Sc. in Computer Science, Department of Computer Science, University of Quebec, Montreal, Canada, 2006.

[56] A. MorCH, Three levels of end-user tailoring: customization, integration and extension. Computers and design in context. MIT Press, Cambridge, MA, USA, 1997.

[57] NCSA ALLIANCE PORTAL, http: //www . extreme.indiana.edu/alliance/

[58] OPEN GRID COLlabORATION ENVIRONMENT (OGCE),

http://www. collab-ogce.org

[59] Open Grid Services Architecture (OGSA), http://www.ggf.org/ogsa-wg/

[60] ORAVEP, Étude comparative technique et pédagogique des plates-formes pour la formation ouverte et à distance. Study report of DT/SDTETIC, 2000. http://dessuticef .ustrasbg.fr/CoursConcepteurs/faerber/Uv_2a/oravep_2000.pdf

[61] V. Pankratius, G. Vossen, Towards ELearning Grids: Using Grid Computing in Electronic Learning. IEEE Workshop on "Knowledge Grid and Grid Intelligence" (in conjunction with 2003 IEEE/WIC International Conference on Web Intelligence/Intelligent Agent Technology), October 13th, Halifax, Canada, 2003.

[62] V. REKLAITIS, Towards e-Learning grid services. Proceedings of World Conference on e-Learning in Corporate, Government, Healthcare, and Higher Education, Phoenix, Arizona, USA, pp. 692-695, 2003.

[63] P. Ritrovato, C. Allison, S. Cerri, T. DimiTRAKOS, M. GAETA, S. SAlERNO, Towards the Learning GRID: advances in Human Learning Services. Volume 127 of Frontiers in Artificial Intelligence and Applications, IOS Press, 2005.

[64] S. ROBERTSON, Understanding Inverse Document Frequency: On theoretical arguments for IDF. Journal of Documentation, 60(5), pp. 503-520, 2004.

[65] E. Sherly, G. Bindya, L. DeEPA, K.-S. Resmy, A Grid Service Based Portal for Virtual Learning Campus. In K. Liew, H. Shen, S. See, W. Cai, P. Fan, S. Horiguchi eds. Parallel and Distributed Computing: Applications and Technologies, Proceedings of the 5th International Conference, PDCAT 2004, Singapore, December 8-10, 2004. Lecture Notes in Computer Science, Springer, 3320, ISBN 3-54024013-6, 86-89, 2004.
[66] TERAGRID, http://www.teragrid.org/

[67] P. Uthayopas, T. ACHALAKUL, Collaborative Eeducation on Thai National Grid System. The 1st International Conference on Digital Media and Learning (ICDML2006), March 13-14, Shangri-la Hotel, Bangkok, Thailand, pp. 12-16, 2006.

[68] L. M. Vaquero-Gonzalez, ET AL. The Opportunity of Grid Services for CSCL Application Development. 13th Euromicro Conference on Parallel, Distributed and Network-based Processing, PDP 2005, Lugano, Switzerland, pp. 4-11.

[69] G. Vega-Gorgojo, et al. Ontoolcole: an ontology for the semantic search of CSCL services. In Proceedings of the 12th International Workshop on Groupware (CRIWG 2006), Medina del Campo, Spain, pp. 310-325, 2006.

[70] F. Xhafa, S. Caballé, T. Daradoumis, N. Zhou, A Grid-Based Approach for Processing Group Activity Log Files. On the Move to Meaningful Internet Systems 2004: OTM 2004 Workshops, October 2529, Larnaca, Cyprus, 2004.

[71] C. T. YANG, H.-C. Ho, An e-Larning platform based on grid architecture. Journal of Information Science Engineering, 21(5), pp. 911-928, 2005.

[72] R. Yatchou, C. Tangha, R. Nkambou, F. TiETCHE, Grid-based virtual clinic for medical diagnosis tutoring. Journal des Sciences Pour l'Ingénieur, 7, pp. 72-78, 2006.

[73] H. Zhuge, Y. LI, KGTutor: A Knowledge Grid Based Intelligent Tutoring System. In Lecture Notes in Computer Science, Springer, 3007, pp. 473-478, 2004.

[74] H. Zhuge, Y. LI, J. BI, T. Cheung, KGCL: A Knowledge-Grid-Based Cooperative Learning Environment. Lecture Notes in Computer Science, NI 2436, Proceedings of the 1st International Conference on Advances in Web-based Learning table of contents, pp. 192-202, 2002.

Received: February, 2009 Revised: November, 2009 Accepted: December, 2009

Contact addresses: Yacine Lafifi Computer Science Department, University of Guelma BP 401 Guelma, 24000 Algeria e-mail: laf_yac@yahoo.fr

Khaled Halimi Computer Science Department, University of Guelma BP 401 Guelma, 24000 Algeria e-mail: h.kaled@yahoo.fr

Mourad Hadjeris Computer Science Department, University of Guelma BP 401 Guelma, 24000 Algeria e-mail: m_hadjeris@yahoo.fr 
YACINE LAFIFI received his $\mathrm{Ph} . \mathrm{D}$. in computer science from the University of Annaba (Algeria) in 2007. He also got the M.S degree in computer science from Annaba University in 2000. He is currently working as an Associate Professor at the Computer Science Department of Guelma University, Algeria. He is also a member of the LAIG laboratory. His current research interests are collaborative learning, CSCL, grid computing, e-Learning, intelligent agents, social networks, and virtual communities.

KHALED HALIMI is a member of the LAIG laboratory. He is currently working as an Assistant Professor at the Computer Science Department of Guelma University, Algeria. He received the M.S degree in computer science from Guelma University in July 2009. Now he is preparing the Ph.D. thesis at Annaba University. His research fields are collaborative learning, virtual communities, and grid computing.

MOURAD HADJERIS is currently working as an Assistant Professor at Computer Science Department, Guelma University, Algeria. He holds the M.S degree in computer science from Annaba University since 2005. Now he is preparing the Ph.D. thesis at Annaba University. His research fields are collaborative learning, semantic web, Web services, and grid computing. 